\title{
Mechanical Properties of Lanthanum Zirconate Based Composite Thermal Barrier Coatings
}

\author{
Jing Zhang ${ }^{1}$, Xingye Guo ${ }^{1,2}$, Yi Zhang ${ }^{1}$, Zhe $\mathrm{Lu}^{3}$, Hyun-Hee Choi ${ }^{4}$, Yeon-Gil Jung ${ }^{4}$, In- \\ Soo Kim ${ }^{5}$ \\ 1. Indiana University - Purdue University Indianapolis, Indianapolis, IN 46202, USA \\ 2. Beijing University of Technology, Beijing, 100124, China \\ 3. University of Science and Technology Liaoning, Anshan, 110870, China \\ 4. Changwon National University, Changwon, Gyeongnam 641-773, Republic of Korea \\ 5. High Temperature Materials Research Group, Korea Institute of Materials Science, \\ Changwon, Gyeongnam, 641-831, Republic of Korea
}

\begin{abstract}
Lanthanum zirconate is a promising candidate material for thermal barrier coating applications due to its low thermal conductivity and high temperature phase stability. However its application is limited by thermal durability caused by low fracture toughness and low coefficient of thermal expansion. We recently developed LZ/8YSZ composite TBC systems using blended LZ and 8YSZ powders, which have demonstrated excellent thermal cycling performance. In this study, the mechanical properties of the composite TBCs were characterized using both nanoindentation and Vicker's microhardness tests. The nanoindentation results show that both the Young's modulus and nanohardness increase with increasing $8 \mathrm{YSZ}$ content, suggesting the mechanical properties can be tailored by changing the volume ratio of $8 \mathrm{YSZ}$. The ratios of the Young's modulus to nanohardness remain constant, $\sim 18$, irrespective to the coating's composition. The microhardness results show the same dependence with $8 Y$ YZ content, which is confirmed by the analytic models based on composite theory.
\end{abstract}

Keywords: Thermal barrier coating; Lanthanum zirconate; Hardness; Young's modulus; Composite

This is the author's manuscript of the article published in final edited form as:

Zhang, J., Guo, X., Zhang, Y., Lu, Z., Choi, H.-H., Jung, Y.-G., \& Kim, I.-S. (2019). Mechanical properties of lanthanum zirconate-based composite thermal barrier coatings. Advances in Applied Ceramics, 118(5), 257-263. https://doi.org/10.1080/17436753.2018.1564415 


\section{Introduction}

Thermal barrier coatings (TBCs) have been extensively used in gas turbines, aircraft and marine propulsion systems to provide thermal insulation to metallic components from hot and corrosive gases $[1,2]$. A typical TBC is composed of four layers of materials, including (1) a substrate of nickel- or cobalt-based superalloy, (2) an oxidation-resistant metallic bond coat of MCrAlY, (3) a thermally grown oxide (TGO) layer, and (4) a ceramic top coat. $8 \mathrm{wt} \%$ yttria doped stabilized zirconia (8YSZ) is the currently used standard TBC material due to its relatively low thermal conductivity $\left(2.12 \mathrm{~W} \cdot \mathrm{m}^{-1} \cdot \mathrm{K}^{-1}\right.$ at $\left.1000{ }^{\circ} \mathrm{C}\right)$, high coefficient of thermal expansions (CTEs, $11 \times 10^{-6} \cdot \mathrm{K}^{-1}$ at $1000{ }^{\circ} \mathrm{C}$ ), good mechanical properties, and chemical inertness in gas turbine operating conditions [3-5]. TBCs are coated using either air plasma spray (APS) or electron-beam physical vapor deposition (EB-PVD) process, in which coating materials are additively deposited on the component surfaces.

Development of advanced TBC materials for advanced gas turbines operated at high temperatures has been an active research area. In general, there are two ways to enhance TBC's performance via reducing the thermal conductivity: (1) feedstock powders with intrinsic low thermal conductivity, and (2) control of top coat's porosity. Recently, a new promising TBC material, lanthanum zirconate $\left(\mathrm{La}_{2} \mathrm{Zr}_{2} \mathrm{O}_{7}, \mathrm{LZ}\right)$ was proposed, which has a pyrochlore structure. Compared with $8 \mathrm{YSZ}, \mathrm{LZ}$ has a lower intrinsic thermal conductivity $\left(1.56 \mathrm{~W} \cdot \mathrm{m}^{-1} \cdot \mathrm{K}^{-1}\right.$ at 1000 ${ }^{\circ} \mathrm{C}$ ), better high temperature phase stability (up to testing temperature $1400{ }^{\circ} \mathrm{C}$ ), and higher sintering resistance [6-8]. However, due to its low coefficient of thermal expansion, high thermal stresses occur near the interface between the top and bond coats, causing delamination and low durability in cyclic thermal environments. Vassen [4, 9-11] and our group [12-26] have developed layered LZ based coatings to mitigate the issue. Double-ceramic-layer (DCL) TBCs have been proposed, which include a top ceramic layer and a thin ceramic buffer layer. In the DCL TBCs, the top layer is made by low thermal conductivity LZ material, which offers good 
heat insulation. The buffer layer is usually made by the traditional TBC materials, usually 8YSZ, which provides CTE mismatch needs with the bond coat. The buffer layer also can be designed with the DCL-TBC as a stress buffer layer, to reduce the stress level and ensure thermal durability [12-15]. Through design of experiment approach, we have identified DCL TBC composed of LZ top layer and porous 8YSZ buffer layer has low thermal conductivity and good thermal cycling durability, comparable to pure 8YSZ coating [12].

Although the initial success, there is a strong motivation to further increase the durability of the TBCs in thermal cycling conditions, in order to meet the requirements of advanced gas turbines. To this end, we recently proposed a new coating architecture with a composite microstructure. The new composite microstructural design employs the blended powders of LZ and $8 Y S Z$ with varying volume ratios. The composite approach is fundamentally different from previous layered microstructures which used single material or same material with varying densities in each layer. Using the new microstructural design, we have demonstrated that the LZ/8YSZ TBC systems have a much better thermal cycling performance than the layered coatings, using a variety of thermal cycling tests, including furnace cyclic thermal fatigue (FCTF), thermal shock (TS), and jet engine thermal shock (JETS) [14].

In this study, we focus on the mechanical properties of the new composite LZ/8YSZ TBC systems, to complement our previous thermal cycling data. The mechanical properties of the as-sprayed TBC specimens were measured using both nanoindentation and microhardness tests. Analytic models of Young's modulus at different LZ/8YSZ ratios were employed based on composite theory. The predicted Young's modulus values were compared with the experimental measurements. 


\section{Experimental procedure}

\subsection{Preparation of TBC specimens}

Nickel-based superalloy ((Nimonic 263, ThyssenKrupp VDM, Germany) was used as the substrate. The dimensions of the substrate were $25.4 \mathrm{~mm}$ in diameter and $5 \mathrm{~mm}$ in thickness. A bond coat (AMDRY 962, Sulzer Metco Holding AG, Switzerland) with a thickness of $150 \mu \mathrm{m}$ was applied between the substrate and top coats. 8YSZ (METCO 204 C-NS, Sulzer Metco Holding AG, Switzerland) and LZ (LAO-109-1, Praxair Surface Technologies, Indianapolis, IN) were blended and used as the feedstock powders for preparing the composite TBCs.

Muli-layered composite coatings were fabricated with varying composites in each layer. The 8YSZ and LZ were premixed with five different volume ratios: 0:100 (pure LZ), 25:75, 50:50, 75:25, and 100:0 (pure 8YSZ). All the composite coatings along with pure 8YSZ and LZ coatings and bond coats were sprayed using air plasma spray (APS) method. Additional preparation details refer to our recent publication [14].

Two types of TBC specimens were selected for this study. The schematics of the two coating designs are shown in Figure 1: (a) Dense 8YSZ/LZ(25\%)+8YSZ (75\%)/LZ(50\%)+8YSZ(50\%)/Porous 8YSZ/Bond coat, and (b) Dense LZ/LZ(75\%)+8YSZ $(25 \%) / \mathrm{LZ}(50 \%)+8 \mathrm{YSZ}(50 \%) /$ Porous $8 \mathrm{YSZ} /$ Bond coat. 


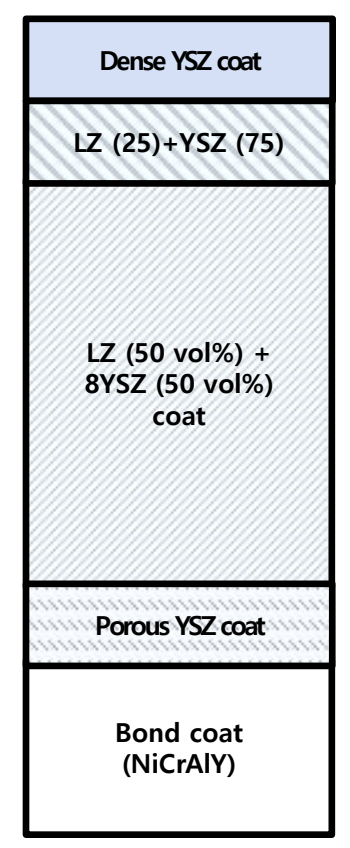

(a)

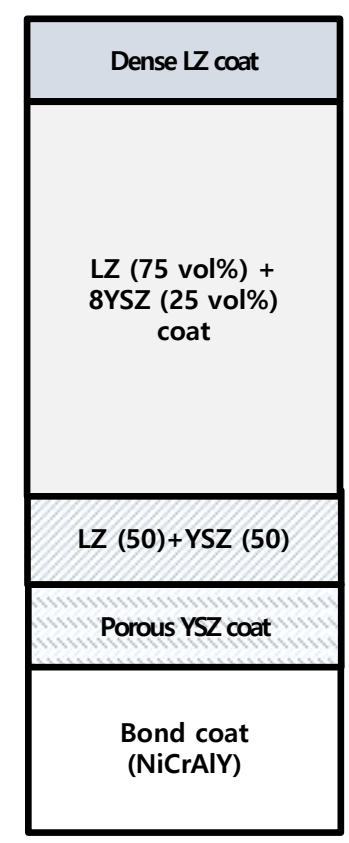

(b)

Figure 1: Schematic of the multi-layer composite TBCs used in study. (a) Dense 8YSZ/LZ(25\%)+8YSZ (75\%)/LZ(50\%)+8YSZ(50\%)/Porous 8YSZ/Bond coat; (b) Dense LZ/LZ(75\%)+8YSZ (25\%)/LZ(50\%)+8YSZ(50\%)/Porous 8YSZ/Bond coat.

2.2 Microstructural, compositional analyses and hardness characterizations of assprayed TBC samples

The as-sprayed composite TBC specimens were preprocessed to observe the crosssectional microstructure and measure the mechanical properties. The mounted specimens were given a final polish with $1 \mu \mathrm{m}$ diamond paste. The cross sectional microstructures of the TBC specimens were observed using a scanning electron microscope (SEM; Model JSM-5610, JEOL, Japan). The chemical composition of each TBC system was determined using an energy dispersive spectrometer (EDS, Oxford Instruments, Oxford, UK). 
For mechanical property characterizations, localized elastic modulus and nanohardness were evaluated using a nano-indenter (Nano Instruments, MTS Systems Corp., Eden Prairie, USA) with a Berkovich tip (radius of tip b100 nm). The data were selected after indentation up to $50 \mathrm{gf}(0.49 \mathrm{~N})$. The global microhardness of the top coats were determined using a microindenter (HM-114, Mitutoyo Corp., Japan) with a Vickers tip for a load of $3 \mathrm{~N}$ and holding for 15 s. To obtain reliable values, more than ten points were tested for each Vickers hardness result. The size of the indentation impression was measured using SEM and all indentations were performed at room temperature. Ten indentations were performed to determine the standard deviation of hardness value [14].

\subsection{Modeling of the Young's modulus of the composite coatings}

In order to understand the role of constitute on the mechanical properties of the composite coatings, we study the Young's modulus with two analytical models based on composite theory: (a) Hashin-Shtrikman (H-S) bounds model [27] and (b) Halpin-Tsai (H-T) model [28] .

The H-S bounds are the tightest bounds possible from range of composite moduli for a two-phase material. The H-S model estimates the upper and lower bounds for modulus of an isotropic spherical aggregate, based on the variational principles of elasticity. Given the volume fraction of the constituent moduli, it allows to predict the upper and lower bounds for the elastic moduli of composite. In the H-S model, the Young's modulus of the composite is calculated from the upper and lower bounds of the bulk moduli, $K_{\text {upper }}$ and $K_{\text {lower }}$, and shear moduli, $G_{\text {upper }}$ and $G_{\text {lower: }}$ :

$$
K_{\text {upper }}=K_{R}+\left(1-V_{p}\right)\left[\frac{1}{K_{M}-K_{R}}+\frac{3 V_{p}}{3 K_{R}+4 G_{R}}\right]^{-1}
$$




$$
\begin{aligned}
& K_{\text {lower }}=K_{M}+V_{p}\left[\frac{1}{K_{R}-K_{M}}+\frac{3\left(1-V_{p}\right)}{3 K_{M}+4 G_{M}}\right]^{-1} \\
& G_{\text {upper }}=G_{R}+\left(1-V_{p}\right)\left[\frac{1}{G_{M}-G_{R}}+\frac{6 V_{p}\left(K_{R}+2 G_{R}\right)}{5 G_{R}+4 G_{R}}\right]^{-1} \\
& G_{\text {lower }}=G_{M}+V_{p}\left[\frac{1}{G_{R}}+\frac{6\left(1-V_{p}\right)\left(K_{M}+2 G_{M}\right)}{5 G_{M}\left(3 K_{M}+4 G_{M}\right)}\right]^{-1}
\end{aligned}
$$

where $V_{p}$ is the volume fraction of reinforcement phase, $8 \mathrm{YSZ}$, and subscripts $M$ and $R$ represent the matrix LZ and reinforcement phase 8YSZ, respectively. The upper and lower bounds of the Young's modulus for each component then are calculated using the following relation:

$$
E=\frac{9 K}{1+(3 K / G)}
$$

The H-T model, on the other hand, is a semi-empirical model that assumes a perfectly oriented discontinuous reinforcement in the composite, parallel to the applied load. It can been used to predict the elasticity of composite material based on the geometry and orientation of the filler and the elastic properties of the filler and matrix. The Young's modulus of the composite for the H-T model is given by:

$$
E_{C}=\frac{E_{M}\left(1+2 s q V_{p}\right)}{1-q V_{p}}
$$

where $E_{C}$ is the Young's modulus of the composite, $E_{R}$ is the elastic modulus of the particle, $E_{M}$ is the modulus of the matrix, and $q$ can be written as:

$$
q=\frac{\left(E_{R} / E_{M}\right)-1}{\left(E_{R} / E_{M}\right)+2 s}
$$


where $s$ is the aspect ratio of the particle. This model assumes that all particles are perfectly aligned with respect to the loading axis, and the aspect ratio $s$ equals to 1 . Additional parameters, including the bulk modulus $K$ and shear modulus $G$ are derived from the Young's modulus and Poisson's ratio by the relations:

$$
\begin{aligned}
& K=\frac{E}{3(1-2 v)} \\
& G=\frac{E}{2(1+v)}
\end{aligned}
$$

\section{Results and discussion}

\subsection{Microstructure and chemical compositions of the composite coatings}

The cross-sectional SEM images of the microstructures of the composite specimens are shown in Figure 2. As shown in both Figure 2 and Figure 1, the coatings have mixed volume ratios in different layers. In both coatings, the top dense layers (LZ or 8YZ) are designed to enhance the erosion resistance of the coating systems. Beneath the dense layer, gradient coating layers provide strain compliance and decrease the thermal expansion mismatch. In Figure 2a, coating architecture LZ(25\%)+8YSZ (75\%) and LZ(50\%)+8YSZ(50\%) is used. In Figure 2b, architecture $\mathrm{LZ} / \mathrm{LZ}(75 \%)+8 \mathrm{YSZ}(25 \%) / \mathrm{LZ}(50 \%)+8 \mathrm{YSZ}(50 \%)$ is employed. In both coatings, a buffer layer made of porous $8 \mathrm{YSZ}$ is added to serve as stress reliever. 
The compositional distributions of lanthanum and zirconium from EDS are also included in Figure 2. Based on the ratios of measured lanthanum and zirconium contents, the composition of the each layer can be estimated, which is consistent with the SEM images.

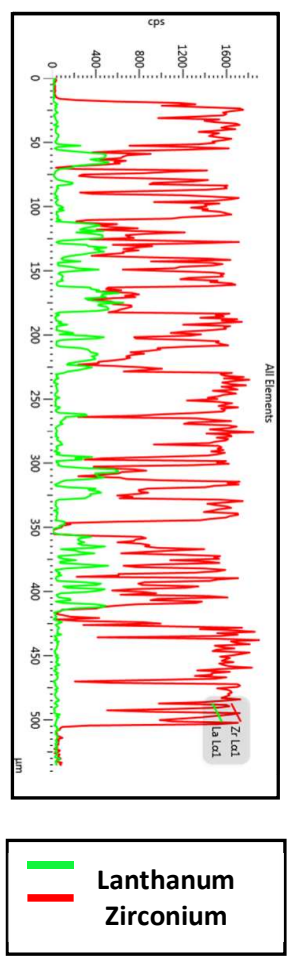

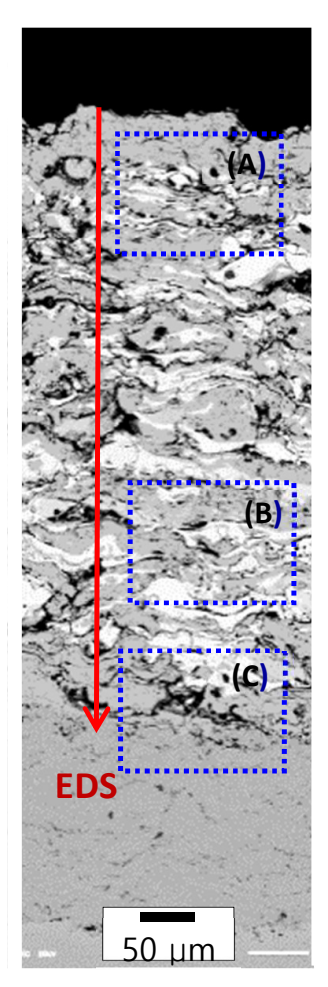

(a)
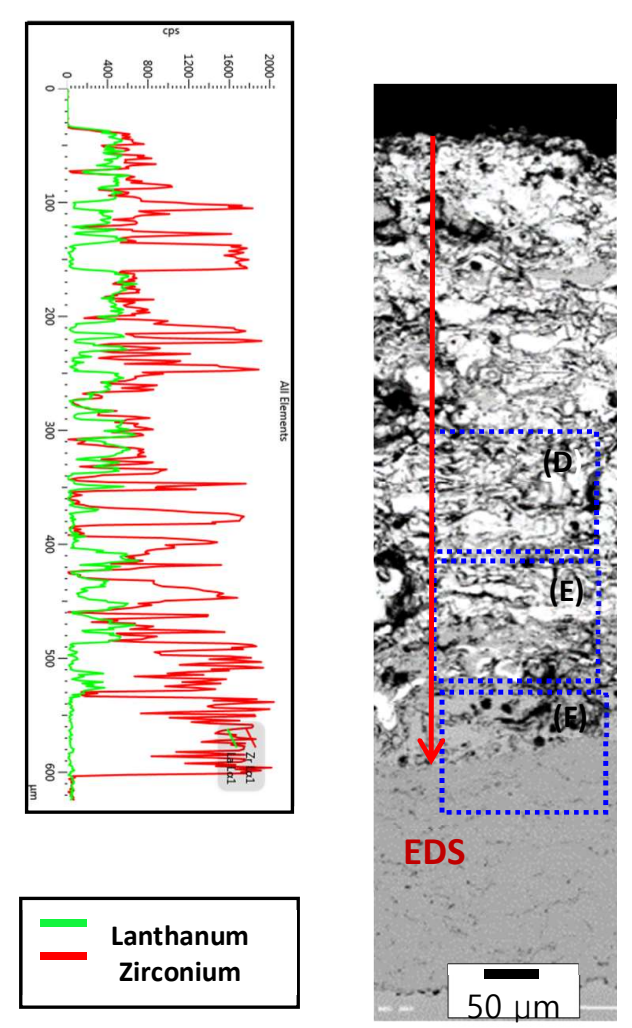

(b)

Figure 2: Cross-sectional microstructures of the composite TBCs prepared with blended powders of 8 YSZ and LZ. The EDS spectra of lanthanum and zirconium are also given. (a) Dense 8YSZ/LZ(25\%)+8YSZ (75\%)/LZ(50\%)+8YSZ(50\%)/Porous 8YSZ/Bond coat; (b) Dense LZ/LZ(75\%)+8YSZ (25\%)/LZ(50\%)+8YSZ(50\%)/Porous 8YSZ/Bond coat. The regions labeled (A-F) are magnified in Figure 3. 
The magnified microstructures in selected regions are shown in Figure 3. The relatively bright and dark regions are the LZ and 8YSZ phases, respectively. As shown in the figure, the microstructures were well controlled, with a lamellar structure. For TBC specimen a, figure 3A shows the interface between the dense $8 \mathrm{YSZ}$ and LZ(25\%)+8YSZ (75\%) layers; figure 3B is the LZ(50\%)+8YSZ(50\%) layer; and figure $3 \mathrm{C}$ shows the porous $8 \mathrm{YSZ}$ layer with the interface with LZ(50\%)+8YSZ(50\%) layer on the top, and bond coat below. For TBC specimen b, figure 3D shows the LZ(75\%)+8YSZ (25\%) layer; Figure 3E shows the interface between the LZ(75\%)+8YSZ (25\%) and LZ(50\%)+8YSZ (50\%) layers; and figure 3F shows the interface between the porous 8 YSZ buffer layer and the substrate.
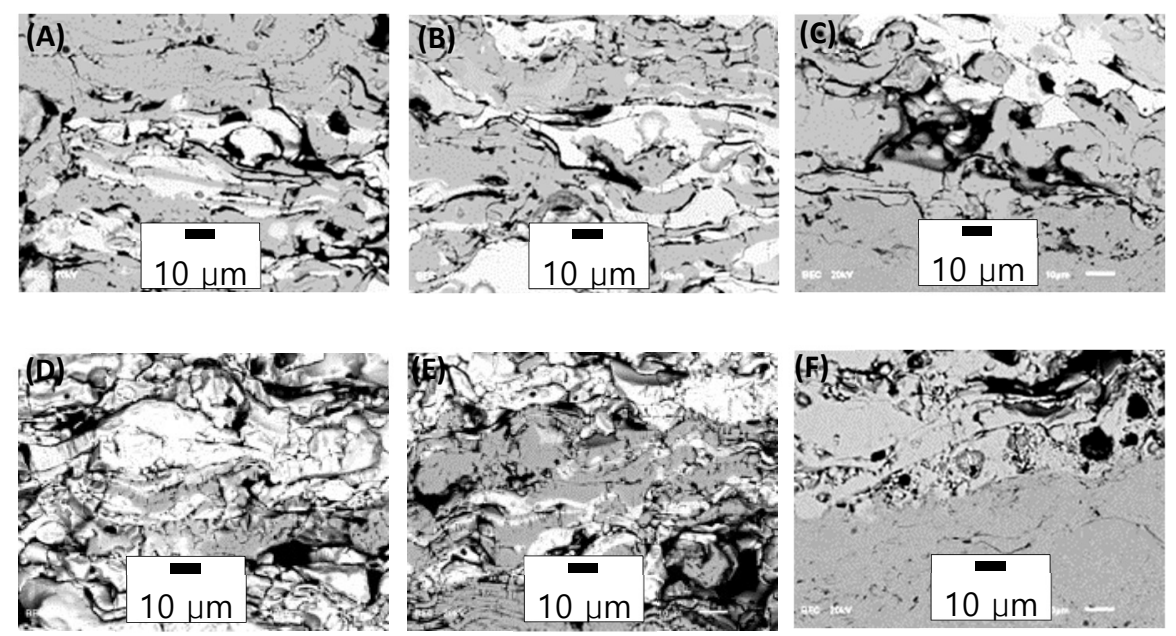

Figure 3: Magnified microstructures in selected regions labeled in Figure 2, where bright color represents LZ, and gray color represents YSZ.

\subsection{Vicker's microhardness}

Using the selected layers in the coating with designated volume ratios shown in Figure 2, the microhardness values were measured, as shown in Figure 4. The indentation mark images 
are also included in the figure. The hardness values of the layers with $100 \% \mathrm{LZ}, 25 \% 8 \mathrm{YSZ}+$ $75 \% \mathrm{LZ}, 50 \% 8 \mathrm{YSZ}+50 \% \mathrm{LZ}, 75 \% 8 \mathrm{YSZ}+25 \% \mathrm{LZ}$, and $100 \% 8 \mathrm{YSZ}$ were determined to be $2.7 \pm 0.3,3.5 \pm 0.5,4.0 \pm 0.2,4.7 \pm 0.3$, and $6.1 \pm 0.3 \mathrm{GPa}$, respectively. The microhardness values of the composite coatings increase almost linearly with increasing content of 8YSZ. The corresponding linear relationship is, through linear regression between the microhardness $(\mathrm{Hv})$ and 8 YSZ volume percentage $(x)$ is: $\mathrm{Hv}=0.032 x+2.6$. The results suggest the global hardness values of the composite coating are reinforced by adding $8 \mathrm{YSZ}$.

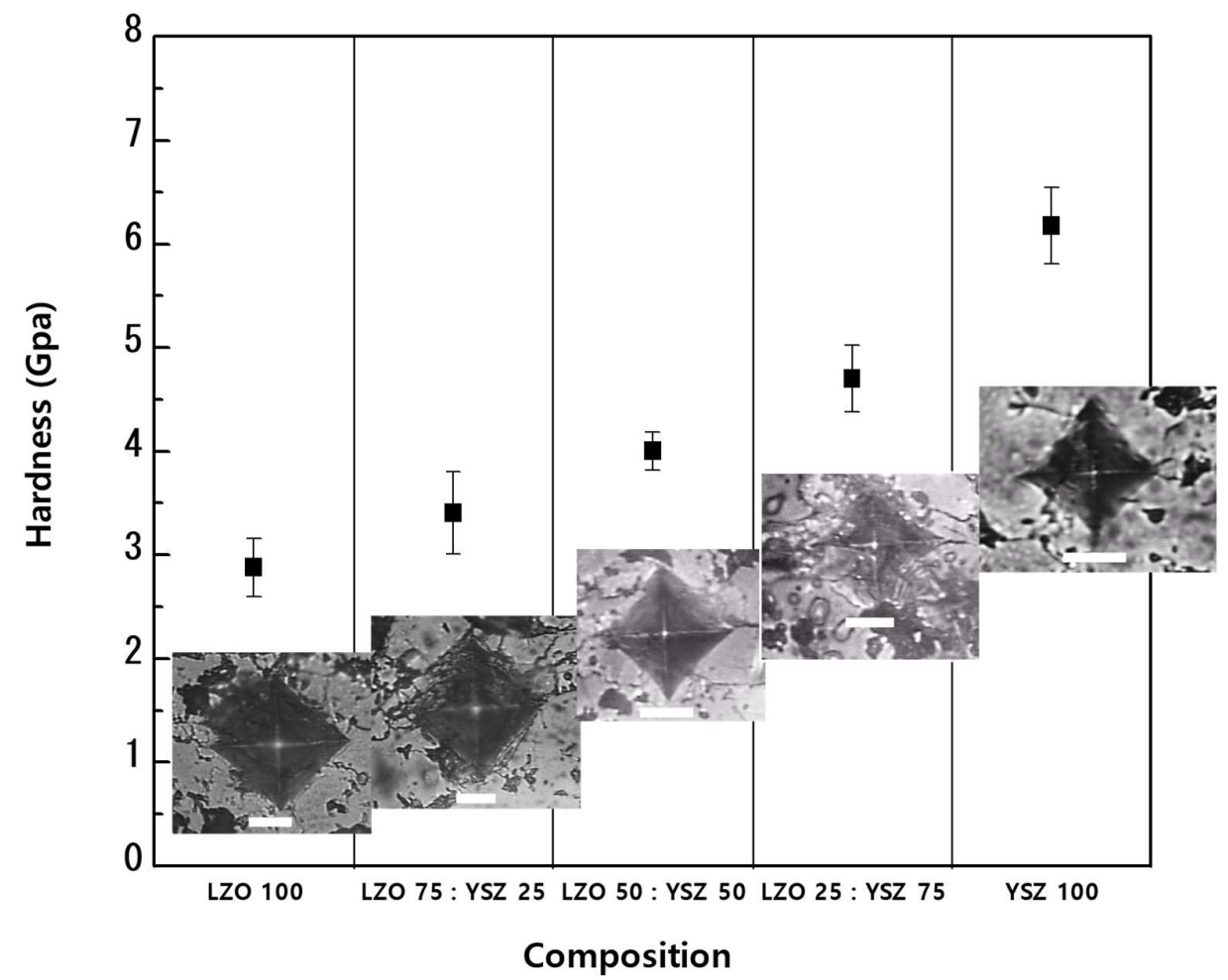

Figure 4: Vickers' microhardness values of as-prepared composite TBCs. The indentation microstructures are also shown. The scale bar is $10 \mu \mathrm{m}$. 


\subsection{Nanohardness and Young's modulus}

The nanohardness and Young's modulus of the composite coatings are given in Figure 5. The nanohardness values of the layers with $100 \% \mathrm{LZ}, 25 \% 8 \mathrm{YSZ}+75 \% \mathrm{LZ}, 50 \% 8 \mathrm{YSZ}+$ $50 \% \mathrm{LZ}, 75 \% 8 \mathrm{YSZ}+25 \% \mathrm{LZ}$, and $100 \% 8 \mathrm{YSZ}$ were determined to be $3.0 \pm 1.0,3.0 \pm 1.1$, $2.5 \pm 1.3,4.5 \pm 2.4$, and $8.5 \pm 2.0 \mathrm{GPa}$, respectively; and the Young's moduli were $60 \pm 10,50$ $\pm 20,53 \pm 16,76 \pm 22$, and $122 \pm 12 \mathrm{GPa}$, respectively. Both nanohardness and Young's modulus increase with increasing $8 \mathrm{YSZ}$ content, similar to the microhardness shown in figure 4. However, nano data show a much larger scattering than the microhardness values. This is because the nanoindentation provides localized mechanical properties, and the results are highly dependent on the coating microstructures.

In Figure 5, it is noted that the Young's moduli of LZ of $25 \% 8 \mathrm{YSZ}+75 \% \mathrm{LZ}$ and $50 \%$ $8 \mathrm{YSZ}+50 \% \mathrm{LZ}$ are slightly lower than that of $100 \% \mathrm{LZ}$, which is likely caused by the high porosity of the coatings. For the same reason, the nanohardness value of $50 \% 8 \mathrm{YSZ}+50 \% \mathrm{LZ}$ is also slightly lower than that of $100 \% \mathrm{LZ}$. 


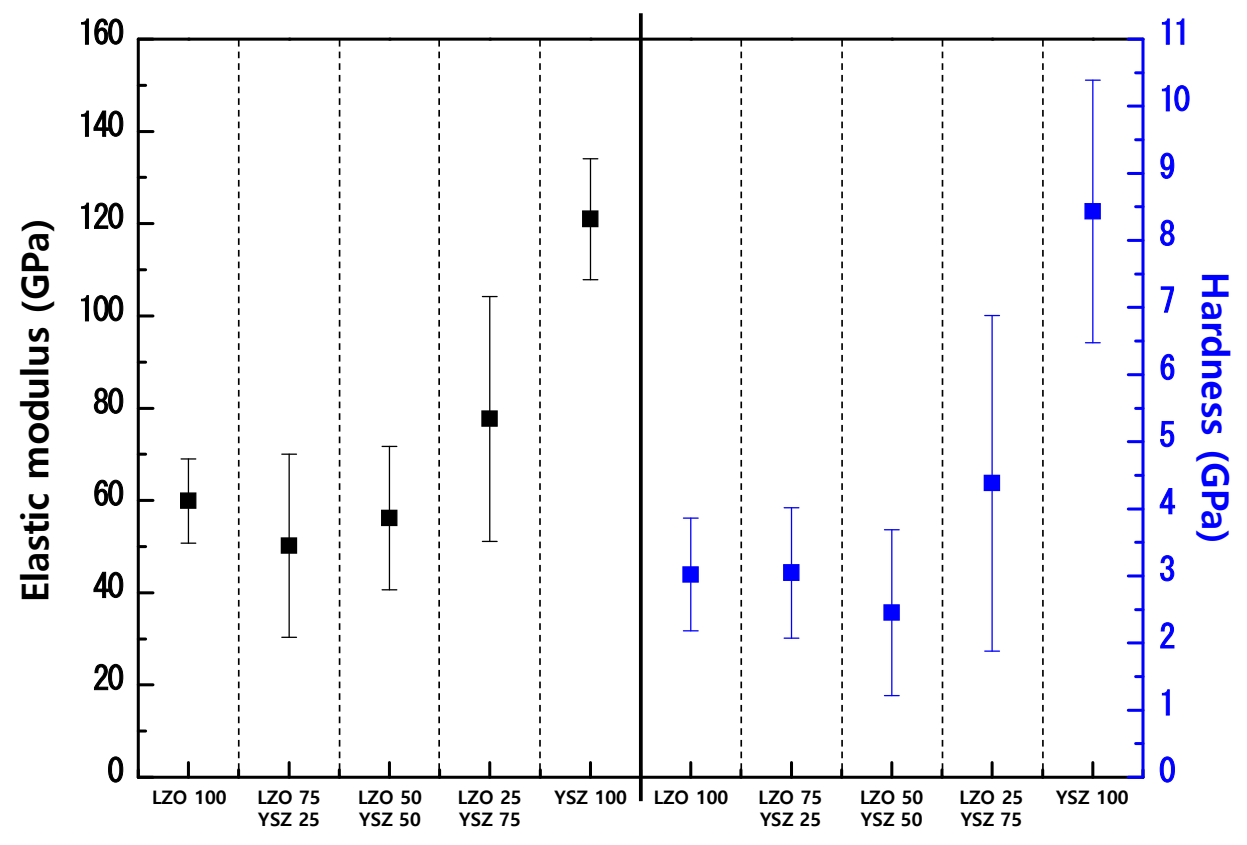

Figure 5: The Young's modulus and nanohardness of as-prepared composite TBCs.

The ratios of the average Young's modulus to nanohardness are plotted in Figure 6. As shown in the figure, the ratios remain basically constant, $\sim 18$, irrespective to the coating's composition. This suggests that in the composite coatings, hardness is linearly correlated to the Young's modulus. 


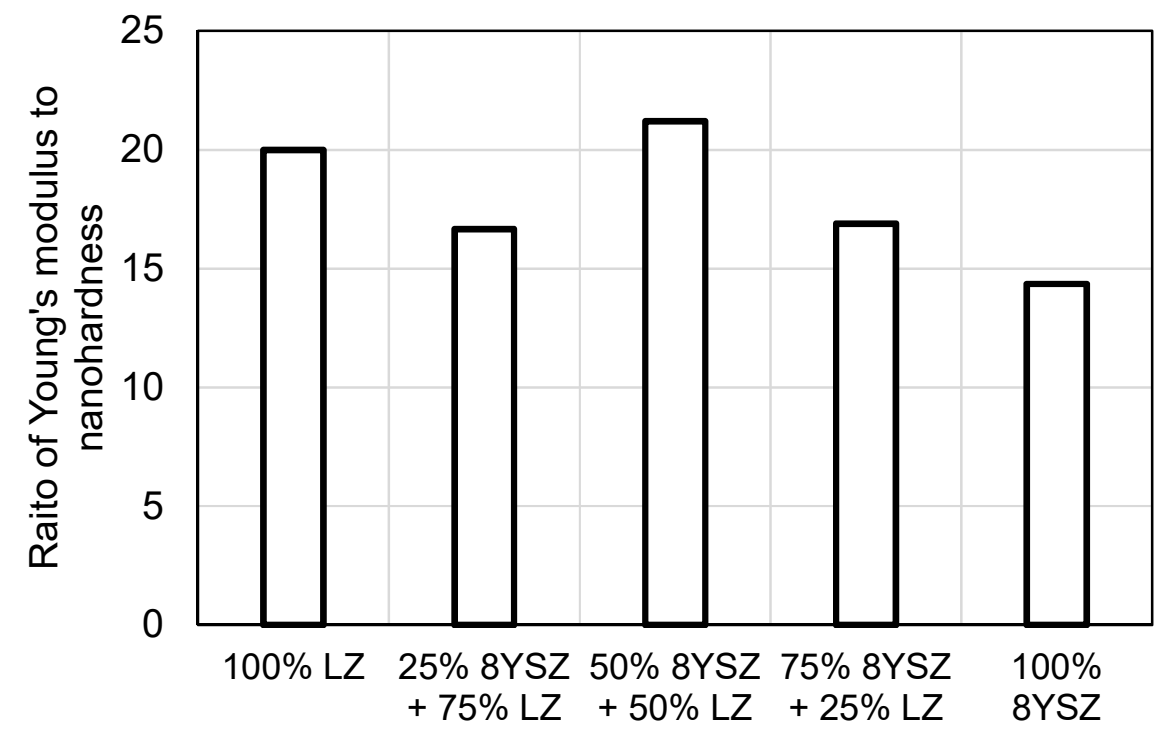

Figure 6: The average Young's modulus to nanohardness ratios of the composite coatings.

Finally, the experimentally measured mechanical properties of the five composite coatings, including nanohardness, Young's modulus, and Vicker's microhardness are summarized in Table 1.

Table 1: Experimentally measured mechanical properties of the composite coatings

\begin{tabular}{|l|l|l|l|l|}
\hline $\begin{array}{l}\text { LZ-8YSZ com } \\
\text { posite } \\
\text { composition }\end{array}$ & $\begin{array}{l}\text { Nanohardness } \\
\text { from } \\
\text { nanoindentation } \\
(\mathrm{GPa})\end{array}$ & $\begin{array}{l}\text { Young's } \\
\text { modulus from } \\
\text { nanoindentation } \\
(\mathrm{GPa})\end{array}$ & $\begin{array}{l}\text { Ratio of } \\
\text { average } \\
\text { Young's } \\
\text { modulus to } \\
\text { nanohardness }\end{array}$ & $\begin{array}{l}\text { Vicker's } \\
\text { microhardness } \\
(\mathrm{GPa})\end{array}$ \\
\hline $\begin{array}{l}100 \% \mathrm{LZ} \\
\begin{array}{l}25 \% \text { 8YSZ }+ \\
75 \% \text { LZ }\end{array}\end{array}$ & $3.0 \pm 1.1$ & $60 \pm 10$ & 20 & $2.7 \pm 0.3$ \\
\hline $\begin{array}{l}50 \% 8 Y S Z+ \\
50 \% \mathrm{LZ}\end{array}$ & $2.5 \pm 1.5$ & $50 \pm 20$ & 17 & $3.5 \pm 0.5$ \\
\hline
\end{tabular}




\begin{tabular}{|l|l|l|l|l|}
\hline $\begin{array}{l}75 \% \text { 8YSZ } \\
25 \% \text { LZ }\end{array}$ & $4.5 \pm 2.4$ & $76 \pm 22$ & 17 & $4.7 \pm 0.3$ \\
\hline $100 \% 8 Y S Z$ & $8.5 \pm 2.0$ & $122 \pm 12$ & 14 & $6.1 \pm 0.3$ \\
\hline
\end{tabular}

3.4 Modeling of the Young's modulus of the composite coatings

Using the Hashin-Shtrikman (H-S) bounds model and Halpin-Tsai model, the Young's moduli of the composite coatings were calculated, as shown in Figure 7. Both models predict the similar trends as the experimental data, i.e., the Young's moduli of the composite coatings increase with the increasing $8 \mathrm{YSZ}$ content. Due to coating's microstructure inhomogeneity and porosity, the predicted bounds do not fully cover the scatter of the experimental data.

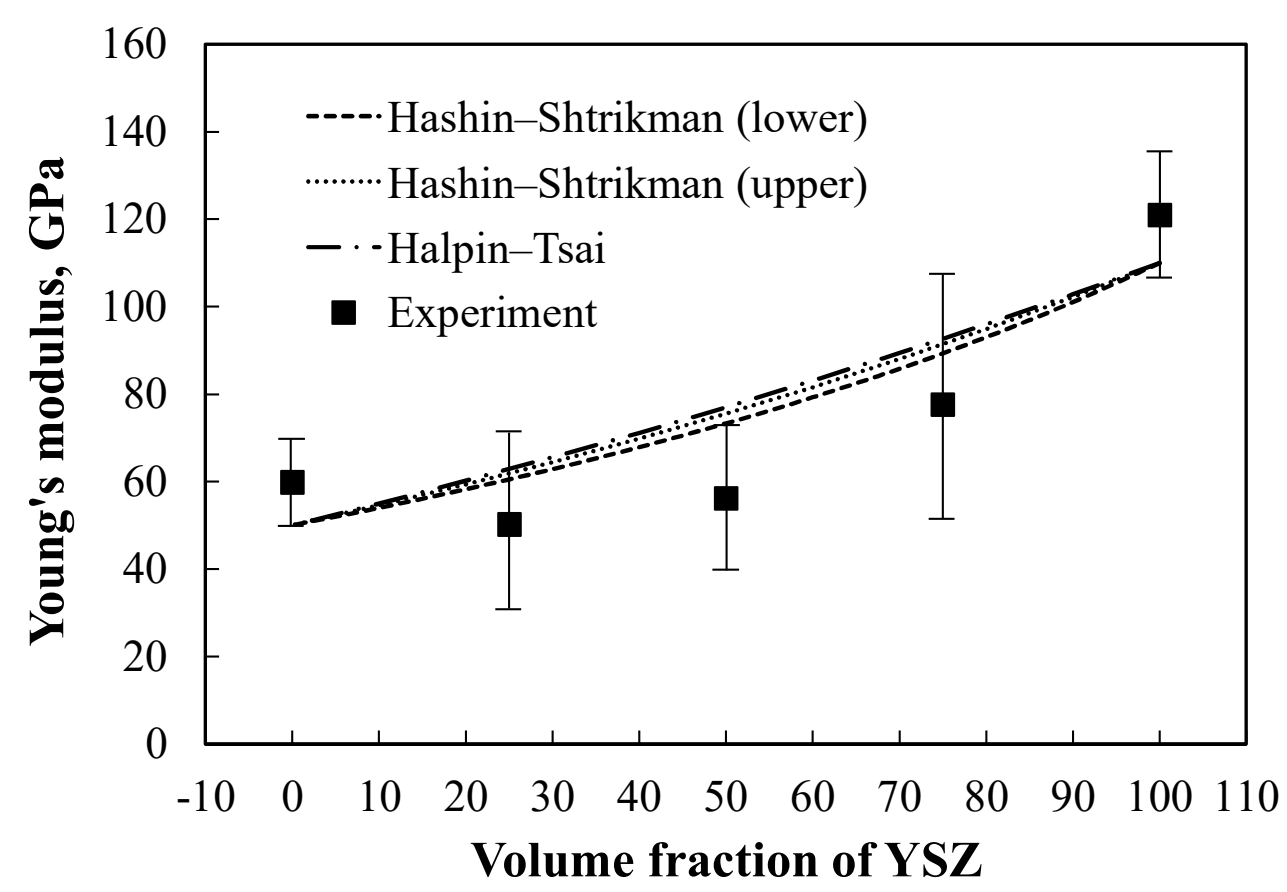

Figure 7: Calculated Young's moduli of the composite coatings. The experimental data are copied from Figure 5. 


\section{Conclusions}

In this work, the mechanical properties of LZ/8YSZ composite TBC systems were systematically characterized using both nanoindentation and Vicker's microhardness tests, along with microstructural and compositional analyses. Five different volume ratios: 0:100 (pure LZ), 25:75, 50:50, 75:25, and 100:0 (pure 8YSZ) were studied. The major conclusions are summarized below.

1. The nanoindentation results show that both Young's modulus and nanohardness increase with increasing $8 \mathrm{YSZ}$ contents, suggesting the mechanical properties can be tailored by changing the composition ratio. The nanohardness values of the layers with $100 \% \mathrm{LZ}, 25 \%$ $8 \mathrm{YSZ}+75 \% \mathrm{LZ}, 50 \% 8 \mathrm{YSZ}+50 \% \mathrm{LZ}, 75 \% 8 \mathrm{YSZ}+25 \% \mathrm{LZ}$, and $100 \% 8 \mathrm{YSZ}$ were determined to be $3.0 \pm 1.0,3.0 \pm 1.1,2.5 \pm 1.3,4.5 \pm 2.4$, and $8.5 \pm 2.0 \mathrm{GPa}$, respectively; and the Young's moduli were $60 \pm 10,50 \pm 20,53 \pm 16,76 \pm 22$, and $122 \pm 12 \mathrm{GPa}$, respectively.

2. The microhardness results show the same dependence with $8 \mathrm{YSZ}$ content. The hardness values of the layers with $100 \% \mathrm{LZ}, 25 \% 8 \mathrm{YSZ}+75 \% \mathrm{LZ}, 50 \% 8 \mathrm{YSZ}+50 \% \mathrm{LZ}, 75 \% 8 \mathrm{YSZ}$ $+25 \% \mathrm{LZ}$, and $100 \% 8 \mathrm{YSZ}$ were determined to be $2.7 \pm 0.3,3.5 \pm 0.5,4.0 \pm 0.2,4.7 \pm 0.3$, and $6.1 \pm 0.3 \mathrm{GPa}$, respectively.

3. The ratios of the average Young's modulus to nanohardness remain constant, $\sim 18$, irrespective to the coating's composition. This suggests that in the composite coatings, hardness is linearly correlated to the Young's modulus.

4. Young's moduli calculated from Hashin-Shtrikman bounds model and Halpin-Tsai model are in good agreement with the trend of experimental measurements. 


\section{Acknowledgements}

J.Z. acknowledges the financial support provided by the U.S. Department of Energy (Grant No. DE-FE0008868, program manager: Richard Dunst) and Indiana University-Purdue University Indianapolis Research Support Funds Grant (RSFG). Y.G acknowledges the financial support provided by "Human Resources Program in Energy Technology (No. 20174030201460)" and "Power Generation \& Electricity Delivery grant (No. 20181110100310)" of the Korea Institute of Energy Technology Evaluation and Planning (KETEP), a granted financial resource from the Ministry of Trade, Industry \& Energy, Republic of Korea. Z.L. acknowledges the financial support provided by the National Nature Science Foundation of China [grant no. 51702145]. 


\section{References}

1. Miller, R.A., Thermal barrier coatings for aircraft engines: history and directions. Journal of Thermal Spray Technology, 1997. 6(1): p. 35-42.

2. DeMasi-Marcin, J.T. and D.K. Gupta, Protective coatings in the gas turbine engine. Surface and Coatings Technology, 1994. 68: p. 1-9.

3. Wang, X., L. Guo, H. Peng, L. Zheng, H. Guo, and S. Gong, Hot-corrosion behavior of a $\mathrm{La}_{2} \mathrm{Ce}_{2} \mathrm{O}_{7} / \mathrm{YSZ}$ thermal barrier coating exposed to $\mathrm{Na}_{2} \mathrm{SO}_{4}+V_{2} \mathrm{O}_{5}$ or $\mathrm{V}_{2} \mathrm{O}_{5}$ salt at $900{ }^{\circ} \mathrm{C}$. Ceramics International, 2015. 41(5, Part A): p. 6604-6609.

4. Cao, X.Q., R. Vassen, and D. Stoever, Ceramic materials for thermal barrier coatings. Journal of the European Ceramic Society, 2004. 24(1): p. 1-10.

5. Xie, X., H. Guo, S. Gong, and H. Xu, Lanthanum-titanium-aluminum oxide: A novel thermal barrier coating material for applications at $1300^{\circ} \mathrm{C}$. Journal of the European Ceramic Society, 2011. 31(9): p. 1677-1683.

6. Bobzin, K., E. Lugscheider, and N. Bagcivan, Thermal Cycling Behaviour of Lanthanum Zirconate as EB-PVD Thermal Barrier Coating. Advanced Engineering Materials, 2006. 8(7): p. 653-657.

7. Saruhan, B., K. Fritscher, and U. Schulz. Y-doped $\mathrm{La}_{2} \mathrm{Zr}_{2} \mathrm{O}_{7}$ pyrochlore EB-PVD thermal barrier coatings. in Ceramic Engineering and Science Proceedings. 2003.

8. Chen, H., Y. Gao, H. Luo, and S. Tao, Preparation and thermophysical properties of La2Zr2O7 coatings by thermal spraying of an amorphous precursor. Journal of thermal spray technology, 2011. 20(6): p. 1201-1208.

9. Cao, X.Q., R. Vassen, F. Tietz, and D. Stoever, New double-ceramic-layer thermal barrier coatings based on zirconia-rare earth composite oxides. Journal of the European Ceramic Society, 2006. 26(3): p. 247-251.

10. Lehmann, H., D. Pitzer, G. Pracht, R. Vassen, and D. Stover, Thermal Conductivity and Thermal Expansion Coefficients of the Lanthanum Rare-Earth-Element Zirconate System. Journal of the American Ceramic Society, 2003. 86(8): p. 1338-1344.

11. Vassen, R., X. Cao, F. Tietz, D. Basu, and D. Stover, Zirconates as New Materials for Thermal Barrier Coatings. Journal of the American Ceramic Society, 2000. 83(8): p. 2023-2028.

12. Guo, X., Z. Lu, Y.-G. Jung, L. Li, J. Knapp, and J. Zhang, Thermal Properties, Thermal Shock, and Thermal Cycling Behavior of Lanthanum Zirconate-Based Thermal Barrier Coatings. Metallurgical and Materials Transactions E, 2016. 3(2): p. 64-70.

13. Jing Zhang, X.G., Yeon -Gil Jung, Li Li, James Knapp, Quantitative analysis of pore morphology in lanthanum zirconate thermal barrier coating. Materials Science and Technology (MS\&T) 2014, 2014: p. 2061-2068.

14. Song, D., U. Paik, X. Guo, J. Zhang, T.-K. Woo, Z. Lu, S.-H. Jung, J.-H. Lee, and Y.G. Jung, Microstructure design for blended feedstock and its thermal durability in lanthanum zirconate based thermal barrier coatings. Surface and Coatings Technology, 2016. 308: p. 40-49.

15. Zhang, J., X. Guo, Y.-G. Jung, L. Li, and J. Knapp, Lanthanum Zirconate Based Thermal Barrier Coatings: A Review. Surface and Coatings Technology, 2016.

16. Guo, X., Z. Lu, H.-Y. Park, L. Li, J. Knapp, Y.-G. Jung, and J. Zhang, Thermal properties of La2Zr2O7 double-layer thermal barrier coatings. Advances in Applied Ceramics, 2018: p. 1-7.

17. Guo, X., L. Li, H.-M. Park, J. Knapp, Y.-G. Jung, and J. Zhang, Mechanical Properties of Layered La2Zr2O7 Thermal Barrier Coatings. Journal of Thermal Spray Technology, 2018. 27(4): p. 581-590. 
18. Lyu, G., B.G. Kim, S.-S. Lee, Y.-G. Jung, J. Zhang, B.-G. Choi, and I.-S. Kim, Fracture behavior and thermal durability of lanthanum zirconate-based thermal barrier coatings with buffer layer in thermally graded mechanical fatigue environments. Surface and Coatings Technology, 2017. 332: p. 64-71.

19. Guo, X., J. Zhang, Y.-G. Jung, L. Li, and J. Knapp. ab initio Study of Thermal Properties of Lanthanum Zirconate. in Materials Science \& Technology 2014 (MS\&T). 2014. TMS.

20. Zhang, J., X. Guo, Y.-G. Jung, L. Li, and J. Knapp, Microstructural non-uniformity and mechanical property of air plasma-sprayed dense lanthanum zirconate thermal barrier coating. Materials Today: Proceedings, 2014. 1(1): p. 11-16.

21. Zhang, J., X. Guo, Y.-G. Jung, L. Li, and J. Knapp. Quantitative Analysis of Pore Morphology in Lanthanum Zirconate Thermal Barrier Coating. in Materials Science \& Technology 2014 (MS\&T). 2014. 2061 - 2068.

22. Guo, X., L. Wu, Y.-G. Jung, L. Li, J. Knapp, and J. Zhang, Carbon dioxide adsorption on lanthanum zirconate nanostructured coating surface: a DFT study. Adsorption, 2015: p. 1-5.

23. Guo, X., L. Wu, Y.-G. Jung, L. Li, J. Knapp, and J. Zhang, Carbon dioxide adsorption on lanthanum zirconate nanostructured coating surface: a DFT study. Adsorption, 2016. 22(2): p. 159-163.

24. Guo, X., L. Wu, Y. Zhang, Y.-G. Jung, L. Li, J. Knapp, and J. Zhang, First principles study of nanoscale mechanism of oxygen adsorption on lanthanum zirconate surfaces. Physica E: Low-dimensional Systems and Nanostructures, 2016. 83: p. 36-40.

25. Lyu, G., B.G. Kim, S.-S. Lee, Y.-G. Jung, J. Zhang, B.-G. Choi, and I.-S. Kim, Fracture behavior and thermal durability of lanthanum zirconate-based thermal barrier coatings with buffer layer in thermally graded mechanical fatigue environments. Surface and Coatings Technology, 2017. 332(Supplement C): p. 64-71.

26. Guo, X., H.-M. Park, L. Li, J. Knapp, Y.-G. Jung, and J. Zhang, Mechanical Properties of Layered La2Zr2O7 Thermal Barrier Coatings. Journal of Thermal Spray Technology, 2018: p. https://doi.org/10.1007/s11666-018-0703-5

27. Hashin, Z. and S. Shtrikman, A variational approach to the theory of the elastic behaviour of multiphase materials. Journal of the Mechanics and Physics of Solids, 1963. 11(2): p. 127-140.

28. Halpin, J. and S. TSAI, AFML-TR-67-423: Environmental factors in composite design. Wright Aeronautical Laboratories, Dayton, 1967. 